\title{
THE PROBLEM OF THAWING PERMAFROST AND METHODS FOR ITS SOLUTION
}

\author{
Yu.S. Tsygankova ${ }^{1 a}$, M.A. Dmitrienko ${ }^{1}$ \\ ${ }^{1}$ National Research Tomsk Polytechnic University, 634050 Tomsk, Russia
}

\begin{abstract}
The review of scientific literature on the problem of thawing permafrost was performed. The main features of different methods for determining the radius of the thing permafrost in the operation of oil and gas wells were marked. The prospects for futher research were identified.
\end{abstract}

\section{Introduction}

A significant part of the large Russian oil and gas fields, which provide up to $70-80 \%$ of oil production in the country, were developed and operated in extreme climatic conditions [1]. The oil production in the conditions of permafrost has some features which are associated with the permafrost properties. The contained in the soil voids moisture at low temperatures solidly "cements" grounds and greatly increases their strength and ability to hold heavy structures loads. However even at "zero" and the more "positive" temperature the frozen ground thaws and lose their strength properties.

The process of drilling wells and oil production constantly provide thermal effect on the permafrost and cause active ice melting. Because of this strong icy soils lose their mechanical properties and decrease in volume. The void and estuarine funnels formed around the wells. They eventually increase in size and lead to loss of the wells stability. As a result the risks of serious accidents with severe environmental consequences arise on deposits, the wells have to stop for a long time to repair, this leads to considerable costs [2] and loss of oil [3].

In order to minimize the problems associated with thawing permafrost it needs to have the tools that would advance at the design stage to predict the thawing ground magnitude and provide the necessary engineering measures to ensure trouble-free operation of oil and gas facilities in the permafrost conditions.

The purpose of this article - to analyze the currently existing methods for determining the scale of thawing permafrost in the wells operation, identify their main features and possibilities for further research in this direction.

\section{Main part}

In the "Rules of safety in the oil and gas industry" [4] noted that the distance between the wells located in a bush should be at least two radii of thawing permafrost. RD 00158758-224-2001 [5]

${ }^{\mathrm{a}}$ Corresponding author : cygankovays@tpu.ru 
regulates the minimum distance between wells in the battery should be 1.2 times larger than the area of thawing permafrost for the 20 years of wells operation. According to the norms of fire safety this distance should be maintained at a level not less than $20 \mathrm{~m}$. Hence the present regulatory framework determines only the principle of the distance selection between the wells located in a bush Hence, the present regulatory framework determines a principle of selection of the distance between the wells located in a bush and does not provide strict recommendations to determine the radius of thawing permafrost for the fields life. The absence of official method for calculating the thawing radius, taking into account the complexity of the many geophysical factors that affect the processes of heat and mass transfer in multi-layer frozen soil, as well as the diversity of approaches to the solution of Stefan problem are of interest from many researchers [1-3, 6-13].

The common feature of most of the known scientific papers [1, 3, 6 - 10 etc.], devoted to the study of thawing permafrost processes around the wells, is the assumption that only conductive heat transfer in a porous medium within the thawed and frozen areas. As a rule, the energy flow in rocks along the well axis is neglected [11]. The second common feature is that the thermal characteristics of freshwater ice are used to calculate the temperature field of permafrost rocks. It is thought [11], that salty ice for one to two years becomes almost unleavened, whereas, prediction calculation thawing of the radii around the wells is carried out usually at intervals of 30 years. The problem of determining the radius of thawing permafrost on the single well is most common [1, 7, $9-11$ etc.].

For example, I. Yu. Bykov and his colleagues used [10] one-dimensional model of the phase transformation process of soils to study the thermal regime of a single well. A rock layer subject to seasonal fluctuations of temperatures divided on two zones (frozen and thawed) with different thermal properties. The important result of [10] is the dependence of the interface between the melt and the permafrost on the time of well operation (fig. 1).

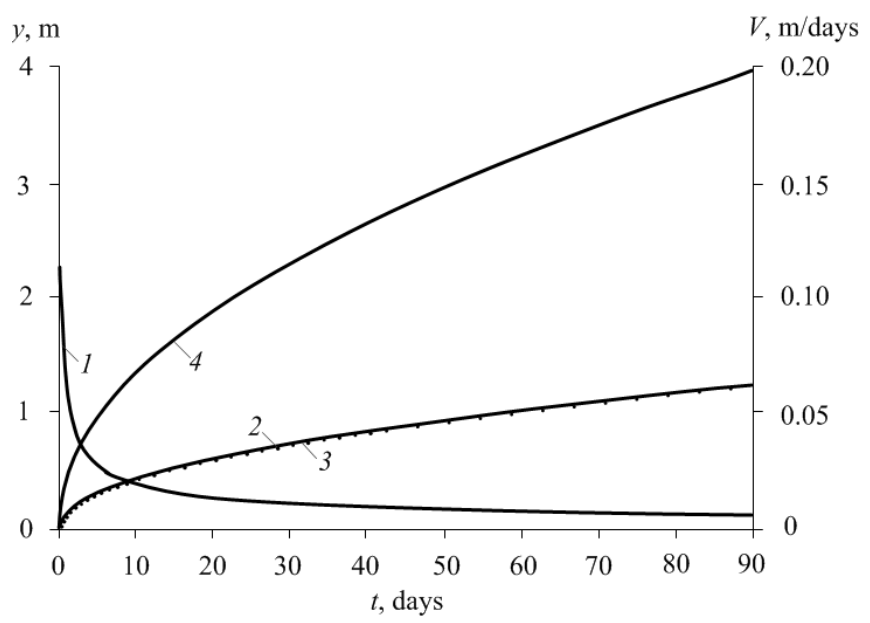

Figure 1. The interface moving between the melt and the permafrost [10]: 2 - the moving of front coordinates "permafrost - thawed rock" taking into account phase transformations, 4 - the same without heat consumption on phase transformations

The comparison of the curve 2 to curve 4, which does not account for the heat loss on the phase transformation (fig.1), allows to conclude about significant influence on the thawing permafrost dynamics of phase transformation. In particular, the thawing front position without phase transformations more than 3 times higher than the value obtained by taking into account the heat loss on the phase transition in permafrost [10].

D.V. Sheveleva solved conjugated problem. It was shown [3] that the dynamic level is one of the factors that significantly affect the thermal calculation of well. In terms of heat transfer it is very important that is in the space between the well and the rocks - gas or oil. The gases have a lower thermal conductivity as compared with liquids. Therefore, the associated petroleum gas that 
accumulates in the space between the well and the permafrost is a heat insulator. It can be seen (fig.2), that the oil temperature change when moving from the bottom to the mouth occurs less intensively when the space behind the well contains a gas (curve 1). On the contrary, the zero dynamic level (the space behind the well is completely filled with oil) the temperature drop most significantly (curve 5). At the interface of gas and oil in the space behind wells (curves $2 \ldots 4$ ) has a pronounced kink, which is caused by a significant difference between the coefficients of thermal conductivity of oil and gas.

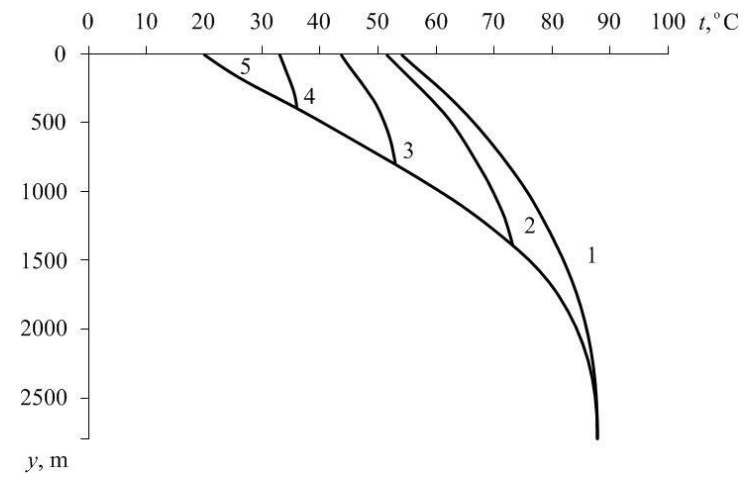

Figure 2. The temperature drop of oil along the well [3]: 1 - at the dynamic level of 2,800 $\mathrm{m} 2$ - at $1400 \mathrm{~m} 3$ - at $800 \mathrm{~m}$, four - at $400 \mathrm{~m} 5$ - at 0

Recently (due to the massive proliferation of cluster drilling method) interest is the study of the processes combined effects of two or more wells in permafrost. Due to the influence of temperature fields from nearby wells radius thawing in the case of the two wells is significantly different from the system with a single well. As shown in [3] under identical conditions the thawing radius of the one well may reach $2.25 \mathrm{~m}$ in 3 years. The thawing zone is a circle. In the case of two wells as a result of superposition their temperature fields thawing area takes an elongated shape in the neighboring well and size of the thawing zone has reached $2.25 \mathrm{~m}$ for 1 year 11 months.

The scientists from the Institute of Earth's Cryosphere Russian Academy of Sciences have led the numerical solution results [6] of the Stefan problem for the two wells in the three-dimensional setting. Heat generation or absorption during the phase transformation was taken into account by adding nonstationary heat equation concentrated heat capacity at the border of phase transition.

The authors [6] neglected by cooling produced gas when lifting it from the bottom to the mouth due to thermal loss and Joule-Thomson effect. But, as shown in [3, 12], the temperature drop can significantly influence the thawing radius of permafrost around the well. In addition, the upper boundary of the solution [6] thermal conductivity and temperature of the surrounding air, which, in fact, essentially depend on the seasonal changes in the weather and snow cover were set constant. Also, the authors [6] did not take into account the heterogeneity of rocks occurrence and changing their thermal characteristics. Therefore the presented thawing zone around the wells have a smooth shape (fig. 3). 


\section{MATEC Web of Conferences}

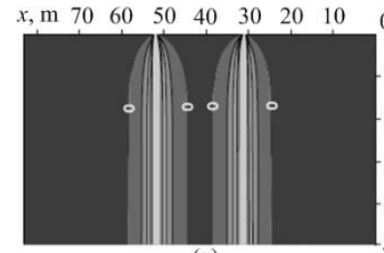

(a)

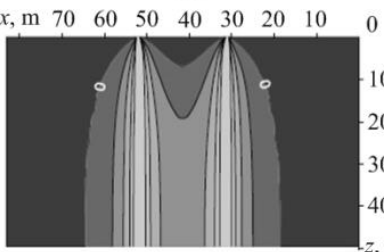

(c)
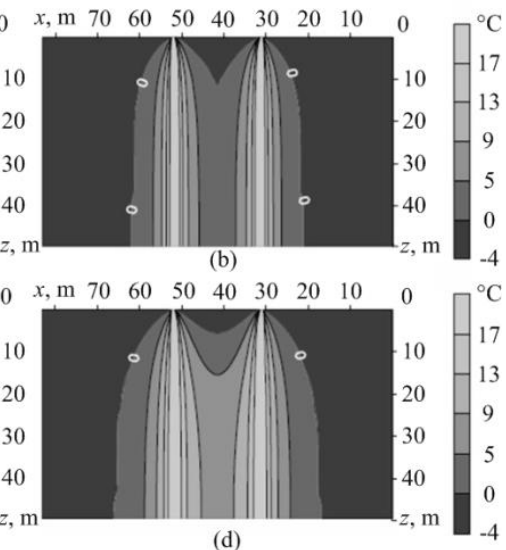

Figure 3. The temperature field in the plane of two wells at different times [6]: a - 10 years, $b-25$ years, $c-40$ years, $d-50$ years

The results obtained in [6], illustrated (fig. 3), that the thermal interaction wells - largely nonstationary process. This follows from the form of the merger of two boundaries of taliks, which in its central part has a sharp kink indicating nonstationarity (fig. 3b, 3c). Further merger of talik (fig. 3d) is characterized by slowing down movement of the phase boundary and the transition process in the quasi-stationary mode. Therefore, the boundary merger of talik over a sufficiently long period of time (fig. 3d) becomes a smooth convex shape similar to a stationary curve.

Quasistationary methods typically do not account for the heat loss for heating rock. Therefore, they understate the rate of thawing and do not give relevant real practice smooth shape of the phase boundary between the wells on the main period of time (fig. 3d).

The calculation model of researchers from the Institute of Mathematics and Mechanics of Russian Academy of Sciences [2] takes into account a significant group of factors influencing the processes of heat and mass transfer in the system "well-permafrost": inhomogeneity of the thermal parameters of soil depth, the effect of the heat absorption in phase transitions in permafrost, seasonal changes in air temperature, the presence on the surface of cluster well foundation backfill of sand and cement, various insulating materials well, the presence of convective and radiative heat transfer on the surface of the real engineering infrastructure of wells providing its insulation from permafrost, and the availability of seasonal cooling devices.

As a basic mathematical model to account for the radiation from a well in [2] used a contact equation (diffusion) with non-uniform thermal conductivity coefficients. The equation included localized heat capacity of the phase transition. This approach allows to solve the problem of the Stefan type, with no explicit separation the phase transition boundary. The heat of the phase change introduced by using the Dirac delta function as concentrated heat capacity of the phase transition in the coefficient of heat. The resulting discontinuous function then "is distributed" over temperature and does not depend on the number of changes and phases. To solve the problem Stefan authors [2] developed a numerical algorithm and a set of applications allowing to model processes thawing of soils for the entire period of well operation.

The authors [13] proposed several options for the development of model [2] with the use of systems with several wells (such formulation of the problem are more relevant [8]).

Despite the consideration of the various factors influencing the heat exchange processes in rocks, the authors [2] did not consider that the phase transformations of moisture from frozen to liquid and back to closed pore space of soils occur in a fairly narrow temperature range. In addition to the model [2], the change of the fluid temperature due to heat loss into the soil through wellbore wall is eliminated from consideration. These assumptions can significantly affect the accuracy of the calculations $[3,12]$. 


\section{Conclusion}

The analysis results of known assessment methods of permafrost thawing in the well operation possible to estimate the impact of various factors on the calculations results to identify the most significant and require mandatory registration.

In the article highlights the modern methods of thermal calculations and shown their limitations with appropriate recommendations on elimination.

The present development level of high-performance computing technology does not limit possibilities for solving the prognostic problem of determining the radius of thawing permafrost taking into account different influencing factors. However the similar problems rather big error in the calculation results made not by the method of solution, but completeness and accuracy of the source data. Often there is no possibility to get information about the soil structure and the their actual thermal properties throughout the depth of study field. At the same time thermal properties of the rock continuously change during operation. The length of geotechnical boreholes giving an idea of the soil structure usually no more than $20 \mathrm{~m}$. While the permafrost in certain regions of our country may be found at a depth of $600 \mathrm{~m}$.

Thus to obtain the necessary thermal calculations of initial data on the properties and structure of permafrost up to now remains a challenge, significantly limits the accuracy of predicting the size of the radius of thawing permafrost in comparison with existing methods of thermal calculation.

\section{References}

1. K.A. Polozkov, Development of methods for monitoring the technical condition of wells in permafrost, Ph.D. dissertation, Moskow, 160 (2009)

2. N.A. Vaganova, V.Yu. Fillimonov, Numerical simulation of thawing permafrost as a result of the exploitation of oil wells. Recent developments in applied mathematics and mechanics: theory, experiment and practice: Conference proceedings - Company RIC «Price-Courier», 5 (2011)

3. D.V. Sheveleva, Dynamics of complex thermal interaction of oil and gas wells with permafrost. Ph.D. dissertation. Tyumen, 181 (2008)

4. Federal rules and regulations in the field of industrial safety «Safety regulations in the oil and gas industry». Series 08. Issue 19. M.: «Scientific and Technical Research Center of Industrial Safety», 288 (2013)

5. RD 00158758-224-2001 Instructions for the simultaneous production of drilling, exploration and exploitation wells in the bush fields far north.- M.: «Gazprom», «TyumenNIIgiprogaz»,11 (2001)

6. Gorelik Ya. B., Shabarov A.B., Sysoev Yu.S. The dynamics of thawing permafrost in the area of influence of the two wells // Scientific journal «Earth's Cryosphere», 2008, t. XII, № 1, P.59-65.

7. VRD 39-1.9-015-2000. Manual photometric method of quality control of construction, mounting of wells in the permafrost and low-temperature rocks. M.: «Gazprom», «VNIIgas», «IRC «Gazprom», 63 (2001)

8. Polozkov K.A. Construction of oil and gas wells on land and at sea, 3, 21 (2008)

9. A.V. Polozkov, Questions exploitation northern gas and gas condensate fields: Collection of scientific papers, 95 (2001)

10. I.Yu. Bykov, V.N. Pushkin,Construction of oil and gas wells on land and at sea, 12, 20 (2009)

11. S.V. Korobkov, Investigation of interaction oil and gas wells with geocryological environment in order to improve their conservation technologies in the northern regions, Ph.D. dissertation, Apatity, 145 (2009)

12. V.N. Petrov, New in the theory and practice of gas fields development, 42 (1966)

13. N.A. Vaganova,V.Yu. Fillimonov, Proceedings of the international scientific-practical conference on permafrost engineering, 410 (2011)

14. T. Zhang, R.G. Barry, K. Knowles, J.A. Heginbottom and J. Brown, Polar Geography, 23 (2), 132 (1999) 